\title{
Application of modified Logistic and Monod models in a single equations system framework to improve cell culture growth modeling and estimation
}

\author{
Mohd Nazri Mohd Fuad ${ }^{1}$ \\ ${ }^{1}$ Universiti Kebangsaan Malaysia
}

December 18, 2020

\begin{abstract}
In modeling cell culture growth using unstructured model, two types of equations are normally used: logistic and Monod. However, these two equations are known for their limitations to model death phase of cell culture growth and to account for dead cells accumulation data. In this paper, we present a modeling framework whereby both Logistic and Monod equations can be used in a single set of equations system to overcome these limitations. First, it can be shown that the increase of total cell population that consists of viable and dead cells follows a logistic growth pattern with its own intrinsic growth rate and total carrying capacity. Furthermore, a hybrid Logistic-Monod equation with first-order decay kinetics can be used to model viable cell growth data with decline phase effectively. With this paradigm, a pseudo-rate equation can be written to account for dead cells accumulation data using population balancing with a simple understanding that dead cell population is simply the difference between total and viable cells. These equations can be adjoined with substrate consumption and product generation rate equations to depict complete batch growth data that covers exponential growth and death phases. This modeling framework has been fitted successfully to fit batch growth data of two cell lines from published literature with complete depictions of dead cell accumulation and cell viability profiles. The implication of this modeling framework for chemostat culture performance analysis is further investigated.
\end{abstract}

\section{Hosted file}

Paper-Modified-Logistic-Monod.pdf available at https://authorea.com/users/379325/articles/ 495557-application-of-modified-logistic-and-monod-models-in-a-single-equations-system-

framework-to-improve-cell-culture-growth-modeling-and-estimation 


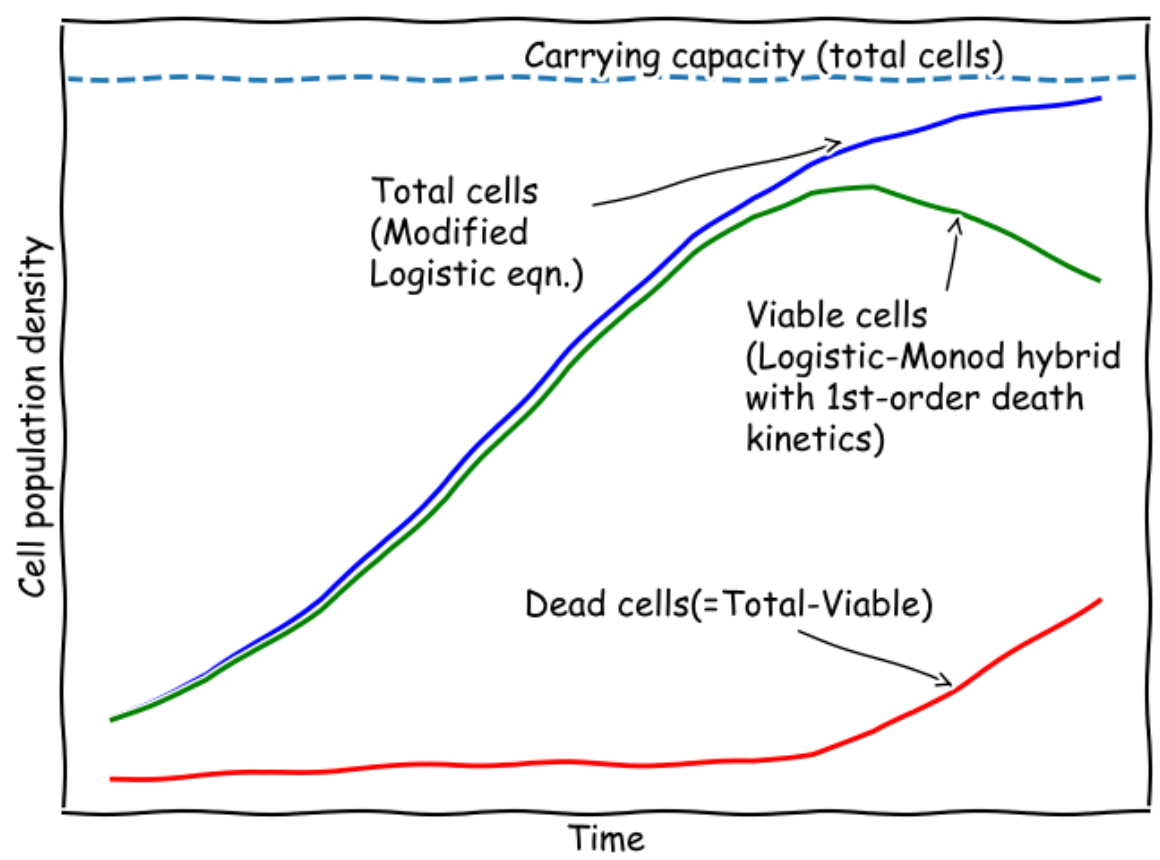

Figure 1: Schematic depiction of the proposed modeling framework 